\title{
A DIGNIDADE DA PESSOA HUMANA COMO FATOR DE IDENTIFICAÇÃO DO BEM COMUM: OBJETIVO DA FUNÇÃO SOCIAL DO ESTADO
}

\section{THE DIGNITY OF THE HUMAN PERSON AS A FACTOR FOR THE IDENTIFICATION OF THE COMMON GOOD: OBJECTIVE OF THE SOCIAL WELFARE OF THE STATE}

\section{Frederico Andrade Siegel ${ }^{1}$}

RESUMO: Este artigo tem a pretensão de identificar o Bem Comum que constitui o objetivo da função social do Estado. O Estado, independente de sua nomenclatura, se caracteriza por sua função social (ou ausência dela). Estados caracterizados pela função social retiraram sua legitimidade do afinamento de suas ações com a função social. Daí resulta a necessidade de identificar o Bem Comum, que constitui objetivo da função social.

Palavras-chave: Estado. Função social. Bem Comum. Dignidade da pessoa humana.
Abstract: This article intends to identify the common good that constitutes the objective of the welfare function of the State. The State, regardless of its nomenclature, is characterized by its welfare function (or absence of it). States characterized by the welfare function have being considered legitimatedue to the linking of their actions to the welfare function. Therefore, it became important to identify the common good, which is the objective of the welfare function.

Keywords: State. Common good. Welfare function. Dignity of the human person.

\section{INTRODUÇÃO}

O presente artigo apresenta algumas nomenclaturas possíveis da categoria Estado, utilizadas para fixá-lo no tempo - Esta-

1 Juiz de Direito no Estado de Santa Catarina, na Comarca de Indaial. Doutorando pela Universidade do Vale do Itajaí (Univali) e pela Universidade de Perugia (Unipg). Mestre em Direito pela Univali e pela Universidade do Minho (Uminho). E-mail: fredericosiegel@gmail.com 
do Moderno ou Estado Contemporâneo - ou para caracterizá-lo de acordo com determinada ideologia (Estado-Liberal, EstadoSocial) ou atividade (Estado-Gerente, Estado-Cientista).

Diante dessa multiplicidade de nomenclatura, não é objetivo deste artigo formular uma definição universal, válida no tempo e no espaço, da categoria Estado. Há uma vasta doutrina que trata da temática (Teoria do Estado), e por conta das limitações inerentes ao artigo, o foco da pesquisa restringiu-se à identificação do Estado por meio do seu elemento caracterizar que pode ser a finalidade ou função social.

O contínuo desenvolvimento do ser humano, como indivíduo, fez surgir novas necessidades sociais, e por conta disso, investiga-se uma possível modificação da finalidade do Estado no decorrer da história humana.

A finalidade também é tratada por parte da doutrina como função social, que possui o Bem Comum como objetivo. Então, buscou-se o conceito operacional de Bem Comum.

A investigação procurou identificar, ainda, o conteúdo do Bem Comum, e encontrou a dignidade da pessoa humana como seu componente. Nesses termos, a noção de dignidade da pessoa humana é apresentada como referência para compreensão do Bem Comum, que constituiu o objetivo da função social ou finalidade do Estado.

\section{A IDENTIFICAÇÃO DO ESTADO DENTRE SUAS INÚMERAS NOMENCLATURAS}

A definição do Estado depende do ponto de partida do seu estudo. É possível definir o Estado a partir da fixação de sua origem e traçar a evolução no tempo - perspectiva histórica -, como também olhar para sua estrutura e identifica-lo mediante gradual formação de seu aparato administrativo (BOBBIO, 2012, p. 54). 
A origem do Estado é apresentada por Dalmo Dallari por meio de três correntes doutrinárias. A primeira sustenta que o Estado surgiu com a formação da sociedade; a segunda refere que por um determinado período, a sociedade existiu sem Estado, o qual surgiu para atender necessidades ou conveniência dos grupos sociais; e a terceira posição defende que "[...] o conceito de Estado não é um conceito geral válido para todos os tempos, mas é um conceito histórico concreto, que surge quando nascem a ideia e a prática da soberania". (DALLARI, 2013, p. 60).

A indagação sobre a identificação do Estado se mostra relevante na medida em que se adicionaram as categorias Moderno ou Contemporâneo. Estas categorias (moderno e contemporâneo - ou como preferem alguns: pós-moderno), portanto, são apresentadas como critério temporal para incluir, na conceituação de Estado, os respectivos elementos identificadores de uma determinada época.

Embora se faça distinção entre Estado Moderno e Estado Contemporâneo, também é possível encontrar referência, nas doutrinas de Paulo Bonavides (BONAVIDES, 2015, p. 55) e Mario Lucio Quintão Soares (SOARES, 2011, p. 60), a respeito de o Estado Moderno estar inserido na realidade contemporânea.

Diante disso, não é possível definir o Estado mediante simples vinculação aos períodos históricos Moderno e Contemporâneo. Aliás, a própria divisão histórica possui certa dose de subjetividade, de tal maneira a ser separada em linhas muito grosserias (DANTAS, 2008, p. 62).

Bobbio refere que o Estado surgiu a partir de sociedades menores, e se tornou o todo de várias partes (sociedades menores, como família e associações). Aos poucos, esse processo se inverteu, e o todo passou à condição de parte da Sociedade. Nesse processo, dois fatores foram contributos: (i) leis econômicas que permitiram convivência harmônica entre os humanos, exigindo mínimo aparato coativo (poder político); 
e (ii) desenvolvimento da organização industrial mantida por cientistas e pelos próprios industriais. Então, conclui Bobbio, "[...] o Estado como sistema político é, com respeito ao sistema social, um subsistema" (BOBBIO, 2012, p. 62).

A passagem do Estado para Estado Moderno encontra justificativa, pela concepção historicista, numa solução de continuidade entre ordenamentos da antiguidade até a idade moderna (BOBBIO, 2012, p. 68).

No entanto, como lembra Bobbio, escolhera definição de Estado a partir dos diversos aspectos possíveis depende de critérios de oportunidade, e não de verdade.

Sejam quais forem os argumentos pró ou contra a continuidade de uma organização política da sociedade, a questão de saber se o Estado sempre existiu ou se se pode falar de Estado apenas a partir de uma certa época é uma questão cuja solução depende unicamente da definição de Estado da qual se parte: se de uma definição mais ampla ou mais estreita. A escolha de uma definição depende de critérios de oportunidade e não de verdade (BOBBIO, 2012, p. 69).

A dificuldade para se estabelecer opinião dominante sobre o conceito de Estado e de Direito - e o problema para resolver a questão entre eles - é denunciada por Hermann Heller (HELLER, 1968, p. 221).

Kant define o Estado como "[...] a união de uma multidão de seres humanos submetida a leis de direito" (KANT, 2008, p. 155). Nesses termos, a definição não encerra o assunto em si mesmo, pois, poderíamos incluir o condomínio edilício na definição que Kant apresentada para a categoria Estado. Isso porque, o condomínio edilício poderia ser definido como o conjunto de seres humanos que se submete à convenção condominial.

Além do aspecto temporal, o Estado pode receber outras denominações que identifica e distingue sua natureza, como visto na História das ideias políticas: Estado-Nação; EstadoSociedade; Estado-Gerente; Estado-Partido; Estado-Força; Es- 
tado-Cientista (CHATELET, 2009, p. 160).

Outras categorias são comumente utilizadas para identificar o Estado, como Estado-Liberal; Estado-Social; Estado Socialista; Estado-Providência; Estado do Bem-Estar.

É importante acrescentar, quanto às nomenclaturas, que Paulo Bonavides distingue Estado Social do Estado Socialista (BONAVIDES, 2009, p. 183), enquanto Paulo Cruz utiliza a expressão Estado do Bem-Estar como sinônimo de Estado Social Democrata ou simplesmente Estado Social (CRUZ, 2011, p. 163).

A formulação de um conceito genérico do Estado, que atenda variáveis de tempo e espaço, poderá implicar num significado poroso. A densidade semântica depende da adição de elementos de identificação à categoria Estado, mas restringem a validade desse conceito no aspecto temporal e geográfico. Ao oferecer um conceito de Estado, este pode ser válido para um determinado momento da história da humanidade e numa região específica do mundo.

Diante das inúmeras nomenclaturas que podem ser atribuídas ao Estado é importante que sua caracterização seja carregada de componentes estratégicos (PASOLD, 2013, p. 22), ou nas já citadas palavras de Bobbio, critérios de oportunidade.

Nesse contexto, destaca-se a criação das normas e sua eficácia, isto é, eficiência, as quais são voltadas para uma finalidade ou função social, como elementos que caracterizam o Estado.

O Estado, segundo Zippelius, não se identifica apenas mediante criação das normas. É necessário que as normas criadas sejam respeitadas, isto é, cumpridas, obedecidas por seus cidadãos. Assim, a realidade estatal decorre da eficiência de suas normas (ZIPPELIUS, 2016, p. 45).

Daí surge a oportuna caracterização do Estado por meio de sua finalidade, tratada num primeiro momento a partir da origem do Estado, e no atual momento. 


\section{A ORIGEM DO ESTADO DE ACORDO COM SUA FINALIDADE}

A origem do Estado pode ser abordada por uma percepção antropológica, por intermédio da qual é possível identificar o início dos agrupamentos humanos, por lanços consanguíneos e/ou afetivos.

Friderich Engels, baseado em relatos de Morgan, que passou a maior parte de sua vida entre os iroqueses - estabelecidos em Nova York - inicia a explicação sobre a formação familiar através do matrimônio por grupos, definido como "[...] a forma de casamento em que grupos inteiros de homens e grupos inteiros de mulheres pertencem-se mutuamente, deixando bem pouca margem para os ciúmes" (ENGELS, 2012, p. 35).

A organização familiar progrediu com a criação de regras que, num primeiro momento, pais e filhos foram excluídos das obrigações sexuais, e posteriormente, foram excluídos os irmãos (ENGELS, 2012, p. 36-37).

Com regras mais apuradas, mas ainda antes da constituição do Estado, define-se uma forma primitiva de organização social denominada gens, que, segundo Morgan, citado por Engels, possuem a mesma essência da tribo de índios americanos, das geneas dos gregos e das gentes dos romanos (ENGELS, 2012, p.81).

A gens tem um conselho, a assembleia democrática de seus membros adultos, homens e mulheres, todos com o mesmo direito de voto. Esse conselho elege e depõe o sachem e o chefe militar, tal como os demais 'guardiões da fé'; decide o preço do sangue (Wergeld) ou a vingança pelo assassinato de um membro da gens; e adota os estrangeiros. Em síntese: é o poder soberano da gens. (ENGLES, 2012, p. 85).

Com a incorporação de seres humanos num mesmo grupo social, criou-se a fratria (irmandade). Várias gens formam uma fratria, e várias fratrias constituem uma tribo. A tribo, por 
sua vez, se caracteriza por ter um território próprio e um nome particular. Em algumas situações, tribos diferentes se uniram numa confederação (ENGELS, 2012, p. 87 e 90).

Engels refere que nos tempos pré-históricos os gregos se constituíram numa forma orgânica semelhante aos americanos: gens, fratria, tribos e confederação de tribos. Esse não era um modelo universal, e em alguns lugares a fratria e a confederação de tribos não chegou a se formar, como entre os dórios. Todavia, "[...] em todos os casos era sempre a gens a unidade" (ENGELS, 2012, p. 95).

Com a repartição da terra e a formação da propriedade privada, a divisão de trabalho entre agricultura e serviços manuais, comércio e navegação, com o estabelecimento do direito hereditário que inclusive poderia incluir cargos púbicos, a riqueza, segundo Engels, passou a ser valorizada como um bem supremo. E para proteger e assegurar a riqueza individual era necessária uma instituição: "E essa instituição nasceu. Inventou-se o Estado". (ENGELS, 2012, p. 103).

A origem e formação do Estado, segundo Engels, teve por finalidade assegurar a propriedade privada e o acúmulo de riqueza. A função do Estado, portanto, já na sua origem, era essa.

Locke também refere o Estado teve por origem a finalidade de proteger a propriedade. Essa, segundo Locke, é a razão dos homens se reunirem em sociedade e aceitarem um governo comum.

O maior e principal objetivo, portanto, dos homens se reunirem em comunidades, aceitando um governo comum, é a preservação da propriedade. De fato, no estado da natureza faltam muitas condições para tanto. (LOCKE, 2006, p. 92).

Locke refere que a propriedade é adquirida pelo trabalho, e para protegê-lo é necessário um Estado estabelecido com leis que assegurem o gozo da propriedade privada. 
Rousseau refere uma dupla finalidade quando trata da origem do Estado. Num primeiro momento, sustenta a necessidade de os indivíduos unirem-se em sociedade visando a própria conservação. E ao assim proceder, os indivíduos somam forças para "[...] conservar o que se tem". (ROUSSEAU, 2002, p. 24).

Por outro lado, Hobbes defende que a origem do Estado teve por finalidade garantir a segurança do indivíduo na medida em que se ocupou e concentrou esforços para evitar a guerra. E para concluir dessa forma, Hobbes analisou a natureza do ser humano.

A abordagem sobre a natureza do ser humano (sensações, pensamentos, linguagem, apetites, paixões, razão) é o ponto de partida de Hobbes para caracterizar o Estado e concluiu que a guerra está na essência da natureza do ser humano.

A liberdade e igualdade dos desejos, apetites, vontades, incitam uma natureza conflituosa entre os seres humanos. As habilidades dos seres humanos são distintas, mas a capacidade de obter aquilo que desejam se compensam. Assim, há uma propensão natural à guerra.

O direito de natureza é definido por Hobbes como a liberdade que o ser humano tem em utilizar seu poder, isto é, suas habilidades, como bem lhe aprouver, com o objetivo de preservar sua vida, e consequentemente, fazer tudo aquilo que for adequado para esse fim.

Segundo Hobbes, o Estado não tem origem em um poder de homens privilegiados e autoproclamados superiores, ou em razão uma classe dominante de indivíduos sobre uma massa humana subordinada. O Estado surge como um poder independente e superior ao homem, com objetivo de impor limites à liberdade, restringindo desejos e paixões os quais, caso não sejam limitados, constituem a causa originária de conflito. A finalidade do surgimento do Estado, então, é assegurar a paz 
e evitar a guerra entre os seres humanos em razão da natureza essencialmente formadora dos indivíduos.

Nesse contexto, Hobbes oferece o conceito de Estado nos seguintes termos:

[...] uma pessoa instituída, pelos atos de uma grande Multidão, mediante Pactos recíprocos uns com os outros, como Autora, de modo a poder usar a força e os meios de todos, de maneira que achar conveniente, para assegurar a Paz e a Defesa comum. O titular dessa pessoa chama-se SOBERANO, e diz que possui poder soberano. Todos os restantes são SÚDITOS (HOBBES, 2008, p. 126).

O ponto comum nessas teorias sobre a finalidade do Estado é a criação de normas, que conduzem o comportamento humana através da força. No entanto, a eficácia da norma não decorre apenas da força. A vontade em obedecer (ROUSSEAU, 2002, p. 6) é um importante elemento de legitimação do Estado.

Com o desenvolvimento das ideias políticas e a evolução das necessidades sociais, a finalidade do Estado se enveredou para outros horizontes.

\section{A FINALIDADE OU FUNÇÃO DO ESTADO (CONTEMPORÂNEO)}

É possível encontrar referência à finalidade do Estado no pensamento de Aristóteles, ao mencionar que "[...] toda cidade é uma espécie de comunidade, e toda comunidade se forma com vistas a algum bem, pois todas as ações de todos os homens são praticadas com vistas ao que lhes parece um bem". (ARISTÓTELES, 1985, p. 1252a).

Todavia, há quem defenda, como Kelsen, que o Estado não possui qualquer finalidade específica (BONAVIDES, 2009 , p. 118). Por outro lado, "[...] outros autores chegam a sustentar que a finalidade é elemento essencial do Estado". (DALLARI, 2013, p. 106). 
Bobbio apresenta duas concepções de Estado: positiva e negativa. Na concepção negativa, o Estado pode ser um mal necessário ou um mal não necessário. Na primeira situação, o Estado deve ser reduzido ao mínimo, pois é visto como algo perverso (mal), mas sua existência é necessária, pela perspectiva de que o Estado é melhor do que Anarquia. Na segunda situação, num determinado momento de evolução social, o Estado terá morte natural, e ainda assim, a Sociedade irá prosperar (BOBBIO, 2012, p. 128-130).

$\mathrm{Na}$ concepção positiva, o Estado possui uma finalidade que está afinada com a ideia de tornar possível a vida do ser humano feliz, ou ainda, de proteger o ser humano de paixões desenfreadas e interesses antagônicos, pois "[...] apenas sob a proteção do Estado o homem pode realizar a própria vida de homem de razão" (BOBBIO, 2012, p. 127).

Dallari refere a existência de três classificações quanto à finalidade do Estado. A primeira distingui fins objetivos e fins subjetivos. A segunda divide os fins do Estado em expansivos, limitados e relativos. E uma terceira distingue os fins em exclusivos e concorrentes (DALLARI, 2013, p. 108-111).

Em relação à primeira classificação:

Os fins objetivos subdividem-se em universais e particulares. No primeiro caso, (todo Estado tem um mesmo fim, e no segundo, cada Estado possui um fim específico, que resultam das circunstâncias de seu surgimento e desenvolvimento. Já os fins subjetivos se caracterizam pelo encontro dos fins do Estado com os fins individuais, vale dizer, os fins do Estado são a síntese dos fins individuais.

Quanto à segunda classificação:

Os fins expansivos crescem até anular o indivíduo e subdividem-se em utilitários e éticos. A ideia de Estado de bem-estar é a linha que caracteriza os fins utilitários, que defende a 
plena satisfação do homem através de uma situação material bem favorável. Esse bem-estar-material é identificado como o bem comum, mas não se confunde com o Bem Comum conceituado pelo Papa João XXIII. Já os fins éticos rejeitam o utilitarismo e defendem a ideia de Estado ético, o qual oferece uma moral oficial.

Nos fins limitados o Estado é reduzido à vigilante da ordem social e não intervêm na ordem econômica. É a linha que orienta o Estado-liberal.

Os fins relativos são baseados na ideia de solidariedade. A cultura geral é produzida pelos indivíduos e pela Sociedade, e não pelo Estado. Então, as atividades humanas "são a expressão de uma solidariedade que existe no íntimo dos indivíduos" e quando externada "cai no círculo das atividades essenciais do Estado".

Tocante à terceira classificação:

Nos fins exclusivos apenas o Estado exerce uma finalidade, que compreende a segurança interna e externa. E nos fins correntes Estado e Sociedade podem ter os mesmos fins.

Ao final da exposição de todas as classificações, Dallari conclui que o Estado possui um fim geral, que é o instrumento de realização dos fins particulares dos indivíduos e da sociedade.

Assim, pois, pode-se concluir que o fim do Estado é o bem comum, entendido este como o conceituou o Papa João XXII, ou seja, o conjunto de todas as condições de vida social que consistam e favoreçam o desenvolvimento integral da personalidade humana. (DALLARI, 2013, p. 112).

Entendo que finalidade do Estado e função do Estado são categorias que se equivalem, pois a função (ação) se completa com o sentido que será dada a ela, o que corresponde à finalidade.

Aqui não estou tratando da função que se esgota em si mesma, v.g, função legislativa, executiva, administrativa, governa- 
tiva dentre muitas outras funções que poderiam ser atribuídas ao Estado. A função a que me refiro é aquela dirigida para um sentido, uma função qualificada pelo propósito.

A função, segundo Dicionário de Filosofia, possui dois significados, um deles (que emprego neste artigo) tem o sentido de operação, ou melhor, de finalidade:

Neste significado o termo corresponde à palavra grega $\mathrm{er}$ gon, do modo como é empregada por Platão, quando diz que a F. dos olhos é ver, a F. dos ouvidos é ouvir, que cada virtude é uma F. de determinada parte da alma, em seu conjunto, é comandar e dirigir (Rep., I, 352 ss). (ABBAGNANO, 2007, p. 472).

Nas palavras de Heller, a Teoria do Estado "[...] pode e deve indagar o sentido do Estado cuja expressão é a sua função social, a sua ação social objetiva". (HELLER, 1968, p. 243).

Ao declarar que o Estado possui uma finalidade ou função social, necessário dizer que suas ações devem estar afinadas com essa finalidade, pena de perder legitimidade.

A legitimidade, segundo Osvaldo Ferreira de Melo, referese "[...] a tudo aquilo que resulte em benefício geral e tenha o respaldo da Sociedade. Nesse sentido, a qualidade do ato e da própria lei deveria identificar-se com as aspirações sociais e com os princípios éticos (Legitimação Ética)" (MELO, 2000, p. 60).

Pasold apresenta o Estado do século XXI como instrumento a serviço da Sociedade (PASOLD, 2013, p. 23). Ao qualificador o Estado como instrumento, é necessário dar-lhe uma utilidade ou função que o conduza a uma finalidade. $\mathrm{O}$ caráter social da função decorre, portanto, de ser um instrumento da Sociedade.

A função social do Estado Contemporâneo é definida por Pasold nos seguintes termos:

A função social deve implicar ações que - por dever para a com a Sociedade - o Estado tem a obrigação de executar, respeitando, valorizando e envolvendo o seu sujeito, aten- 
dendo o seu objeto e realizando os seus objetivos, sempre com a prevalência do social e privilegiando os valores fundamentais do ser humano. (PASOLD, 2013, p. 57).

O objetivo do Estado, que compõe a definição da função social, é a "[...] concretização do Bem Comum, conforme o que for estabelecido pela Sociedade" (PASOLD, 2013, p. 35).

No dicionário de filosofia de Nicola Abbagnano bem é definido como "[...] tudo o que possui valor, preço, dignidade, a qualquer título". (ABBAGNANO, 2007, p. 107).

Bem Comum possui a seguinte definição para Washington dos Santos: "Bens e condições sociais que possibilitam a felicidade coletiva para vida humana, de ordem material e imaterial" (SANTOS, 2001, p. 44).

Segundo Osvaldo Ferreira de Melo, Bem Comum pode possuir duas acepções:

1. Fim político subordinado à moral que pretensamente pode ser alcançado pelos cidadãos, desde que estejam unidos por sentimentos de solidariedade. Para que funcionem as estratégias montadas para a obtenção desse fim, é indispensável a existência, na Sociedade em questão, de um mínimo de consenso sobre valores sociais como Solidarismo (V). 2. Diz-se também dos fatores propiciados pelo Estado com vistas ao bem-estar social. (MELO, 2000. p. 15).

Diante de tais premissas, é possível compreender que Bem Comum é um valor compartilhado pelos seres humanos, que constitui o objetivo da função social do Estado Contemporâneo.

\section{IDENTIFICAÇÃO DA DIGNIDADE DA PESSOA HUMANA}

A dignidade da pessoa humana surgiu com força normativa ao final da II Grande Guerra. Está mencionada no preâmbulo da Carta da ONU de 1945, bem como no preâmbulo e artigos $1^{\circ} \mathrm{e}$ 23 da Declaração Universal dos Direitos Humanos de 1948. 
José Afonso da Silva refere que a Lei Fundamental da República Federal da Alemanha foi quem, por primeiro, erigiu a dignidade da pessoa humana como direito fundamental (SILVA, 2007, p. 144).

A partir de então, outros Estados passaram a incluir a categoria dignidade da pessoa humana no respectivo texto constitucional, como ocorreu em Portugal, Espanha e Brasil (SILVA, 2007, p. 144). Importante esclarecer que, para fins deste artigo utilizo as expressões "dignidade da pessoa humana" e "dignidade humana" como sinônimos.

No caso brasileiro, a dignidade da pessoa humana está prevista como fundamento do Estado Democrático de Direito, conforme se lê no art. $1^{\circ}$, inciso III, da Constituição da República Federativa do Brasil de 1988.

Embora prevista em textos constitucionais, não é neles que se encontra o conceito da categoria dignidade da pessoa humana. Aliás, a dignidade humana não é uma criação constitucional, mas um valor supremo da ordem jurídica, ao ser declarada como fundamento do Estado Democrático de Direito (SILVA, 2007, p. 146).

Todavia, instituir a dignidade da pessoa humana como fundamento do Estado, ou reconhece-la como valor supremo, não é bastante para compreender seu significado e alcance.

É dizer: a categoria dignidade humana só terá sentido se o seu conteúdo for revelado, ainda que de forma incipiente; ainda que seu conteúdo seja constantemente revisto pelo critério histórico-social.

A dignidade da pessoa humana, então, terá valor (supremo) na ordem jurídica, suficiente para afetar direitos, somente quando houver mínima definição a seu respeito.

A ausência de definição normativa a respeito dignidade da pessoa humana pode implicar na banalização dessa categoria, 
pois cada um se arvora no direito de se apropriar da expressão e utilizá-la como bem entender. Aliás, essa banalização já foi denunciada por Luís Roberto Barroso em dois casos julgados pelo Supremo Tribunal Federal em 2011 (BARROSO, 2014, p. 117).

Ainda, Barroso refere que referências à dignidade da pessoa humana tem se multiplicado nas decisões proferidas pelo Superior Tribunal de Justiça nas mais diversas áreas do direito (BARROSO, 2014, p. 119).

Nesse contexto, é necessário que se construa definição mínima a respeito da categoria dignidade da pessoa humana, justamente para que se compreenda seu conteúdo e alcance, de forma a ser utilizada da melhor maneira possível.

A definição de dignidade humana não tem surgido da democracia, senão da democracia qualificada. E é dessa fonte democrática qualificada que se extrai sua legitimidade, quando utilizada para resolução de conflitos sociais.

Para fins desse artigo, utilizo a categoria democracia como sinônimo de democracia representativa com o seguinte conceito operacional: sistema de organização do Estado segundo o qual o Poder é exercido pelo povo através de seus representantes, eleitos em eleições periódicas.

A democracia qualificada, para fins deste artigo, possui o seguinte conceito operacional: sistema de organização do Estado segundo o qual o Poder é exercido em nome do Povo por pessoas que possuem a qualificação profissional para exercê-lo.

Luís Roberto Barroso define a dignidade humana nos seguintes termos:

[...] a dignidade humana identifica: 1 . O valor intrínseco de todos os seres humanos; assim como 2. A autonomia de cada indivíduo; e 3. Limitada por algumas restrições legítimas impostas a ela em nome de valores sociais ou interesses estatais (valor comunitário). (BARROSO, 2014, p. 73). 
Ingo Sarlet oferece o seguinte conceito operacional para a categoria dignidade da pessoa humana:

[...] temos por dignidade da pessoa humana a qualidade intrínseca e distintiva reconhecida em cada ser humana que o faz merecedor do mesmo respeito e consideração por parte do Estado e da comunidade, implicando neste sentido, um complexo de direitos e deveres fundamentais que assegurem a pessoa tanto contra todo e qualquer ato de cunho degradante e desumano, como venham a lhe garantir as condições existenciais mínimas para uma vida saudável, além de propiciar e promover sua participação ativa e coresponsável nos destinos da própria existência e da vida em comunhão com os demais seres humanos, mediante o devido respeito aos demais seres que integram a rede da vida. (SARLET, 2015, p. 70-71).

Eros Grau apresentada a dignidade da pessoa humana pela perspectiva da ordem econômica, ao mencionar que toda atividade econômica, seja ela em sentido amplo ou em sentido estrito, deve estar comprometida em promover a existência digna da qual todos devem gozar. E acrescenta que o setor público e privado devem ser empenhar na realização desse programa (GRAU, 2015, p. 194-195).

Então, se a dignidade do ser humano (ou da pessoa humana) é um valor, portanto, um bem; se todos devem gozar de uma existência digna; e se a dignidade deve ser promovida pelo setor público (ainda que de forma concorrente com privado), conclui-se que a dignidade da pessoa humana constituiu o Bem Comum que constitui objetivo da função social do Estado Contemporâneo.

\section{CONCLUSÃO}

No presente artigo foi visto que o Estado possui diversas nomenclaturas que são utilizadas para identificá-lo, que podem guardar relação com a época em que está situado na linha do tempo; com uma determinada ideologia ou ainda, 
com uma atividade.

Diante disso, surge a necessidade de caracterizar o Estado por meio de sua finalidade, o qual, como visto, pode possuir mais de uma. No entanto, seja para assegurar e garantir a propriedade, ou para resguardar a segurança do indivíduo - evitando a guerra - o ponto comum que pode caracterizar o Estado é um conjunto de normas que tenha o mínimo de eficácia mediante utilização legítima da força

Com o surgimento de novas ideias políticas sobre os rumos que o Estado deveria adotar, especialmente sobre a finalidade ou função social do Estado, o conceito de dignidade da pessoa foi apresentado como protagonista nesse contexto. Isso porque, como visto, a dignidade humana é interpretada no papel central do objetivo do Bem Comum, que constitui a finalidade do Estado Contemporâneo. A ideia de Bem Comum, portanto, vem relacionada com o valor de identidade de todos os seres humanos.

A importância de identificar o objetivo do Estado (Bem Comum) reside justamente nas suas ações. Todas as ações do Estado devem ser animadas por um determinado objetivo. A legitimidade da atuação do Estado decorre, portanto, do afinamento de suas ações com o seu objetivo.

O direito não decorre apenas da força, mas também, e principalmente da vontade em obedecer às regras estipuladas. Logo, num modelo democrático no qual o poder da elaboração do direito emana do povo, o Estado alcança e mantem a legitimidade dos seus atos na medida em que estes atos ou ações (materializados na elaboração e execução das normas) atendam ao objetivo do Bem Comum.

A finalidade que caracterizou a origem do Estado como visto estava identificada com a segurança do indivíduo ou o resguardo da propriedade. Todavia, nesse atual período histórico da humanidade, a finalidade do Estado é alçada a um novo 
patamar, agora identificada pela dignidade da pessoa humana.

É nesse contexto, portanto, que a dignidade da pessoa humana é definida como um valor de identificação dos seres humanos, com a qual o Estado está comprometido, ou melhor, constitui seu fundamento, sua essência.

Então, é possível concluir que a dignidade da pessoa humana integra a definição de Bem Comum, que constitui o objetivo da função social do Estado.

\section{REFERÊNCIAS}

ABBAGNANO, Nicola. Dicionário de filosofia. Tradução da 1 ed. por Alfredo Bossi. Tradução de novos textos incluídos na 5 ed. por Ivone Castilho Benedetti. 5 ed. São Paulo: Martins Fontes, 2007.

ARISTÓTELES. Política. Tradução de Mario da Gama Kury. Brasília: Editora Universidade de Brasília, 1985.

BARROSO, Luís Roberto. A dignidade da pessoa humana no direito constitucional contemporâneo: a construção de um conceito jurídico à luz da jurisprudência mundial. 3. reimp. Belo Horizonte: Fórum, 2014.

BOBBIO, Norberto. Estado, governo, sociedade: por uma teoria geral da política. Tradução de Marco Aurélio Nogueira. Rio de Janeiro: Paz e Terra, 2012. Título original: Stato, governo, società: per una teoria generale dela politica.

BONAVIDES, Paulo. Do Estado liberal ao estado social. 9. ed. São Paulo: Malheiros, 2009.

CHÂTELET, François. História das ideias políticas. Tradução de Carlos Nelson Coutinho. 2. ed. Rio de Janeiro: Zahar, 2009. Título original: Histoiredesidées politiques.

CRUZ, Paulo Márcio. Política, poder ideologia e estado contemporâneo. 3. ed. Curitiba: Juruá, 2011.

DALLARI, Dalmo de Abreu. Elementos de teoria geral do estado. 32. ed. São Paulo: Saraiva, 2013.

DANTAS, Ivo. Teoria do estado contemporâneo. Rio de Janeiro: Forense, 2008.

ENGELS, Friderich. A origem da família, da propriedade privada e do Estado. Tradução de Ruth M. Klaus. 4 ed. São Paulo: Centauro, 2012. Título original: Der Ursprung der Familie, des Privateigentaums des Staats.

GRAU, Eros Roberto. A ordem econômica na Constituição de 1988.17. ed. rev. atual. São Paulo: Malheiros, 2015.

HELLER, Hermann. Teoria do estado. Tradução de Lycurgo Gomes da Motta. São Paulo: Mestre Jou, 1968. Título original: Staatslehre. 
HOBBES, Thomas. Leviatã: ou a matéria, forma e poder de um estado eclesiástico e civil. Tradução Rosina D’Angina. 3. ed. São Paulo: Ícone Editora, 2008.

KANT, Immanuel. A metafísica dos costumes. Tradução de Edson Bini. 2. ed. Bauru: Edipuro, 2008. Título original: Die Metaphysik der Sitten.

LOCKE, John. Segundo tratado sobre o governo. Tradução de Alex Martins. 2. ed. São Paulo: Martin Claret, 2006. Título original: Two.Treatises.of.Government.

MELO, Osvaldo Ferreira de. Dicionário de política jurídica. Florianópolis: ed. OAB-SC, 2000.

PASOLD, Cesar Luiz. Função social do estado contemporâneo.4. ed. rev. amp. Itajaí/ SC: Univali, 2013.

ROUSSEAU, Jean-Jaques. O contrato social. Tradução de Rolando Roque da Silva. Edição eletrônica Ridendo Castigat Mores (www.jahr.org), 2002.

SANTOS, Washington dos. Dicionário jurídico brasileiro.Belo Horizonte: Del Rey, 2001.

SARLET, Ingo Wolfgang. Dignidade (da pessoa) humana e direitos fundamentais na Constituição Federal de 1988.10. ed. rev. atual. amp. Porto Alegre: Livraria do Advogado, 2015.

SILVA, José Afonso da. Poder constituinte e poder popular (estudos sobre constituição). São Paulo: Malheiros, 2007.

SOARES, Mario Lucio Quintão. Teoria do estado: novos paradigmas em face da globalização. São Paulo: Atlas, 2011.

ZIPPELIUS, Reinhold. Teoria geral do estado. Tradução de António Franco e António Francisco de Souza. São Paulo: Saraiva, 2016. Título original: Allgemeine Staatslehre politique wissens chaft.

Artigo recebido em: 25/05/2017

Artigo aprovado em: 02/10/2017 